\title{
2011 Canadian Association of Gastroenterology educational needs assessment report
}

\author{
Craig Render MD, VP CAG Education Affairs \\ Sandra Daniels MSc, CAG National Office
}

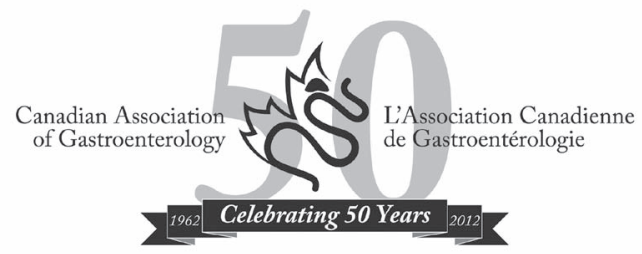

$\mathrm{T}$ he annual survey of Canadian Association of Gastroenterology (CAG) members' educational needs was conducted via an online survey during March and April. A total of 205 individuals completed the survey. Similar to previous years, inflammatory bowel disease (IBD) topics were most in demand for future educational events. Other highly rated areas were the following: celiac disease, endoscopic techniques and therapeutics, and live endoscopy. Of those who had an opinion on the subject, $58 \%$ preferred that Canadian Digestive Diseases Week (CDDW) be held at a resort over a major airport hub. More than two-thirds of respondents supported CAG providing speakers or content for regional/provincial gastroenterology society meetings. Approximately one-half were aware of the launch of CAG's educational portal (ePortal) in 2009 and 31\% had visited the site. Those familiar with the ePortal overwhelmingly agreed that it was valuable, easy to use and that they would visit again.

\section{INTRODUCTION}

The purpose of the CAG needs assessment was to provide guidance to the Executive and CAG Education Affairs on areas of greatest educational need. Conducting a needs assessment is a requirement for accreditation of educational events in accordance with the Royal College of Physicians and Surgeons of Canada (RCPSC).

\section{METHODS}

The members of Education Affairs 2011 include the following: Drs Lana Bistritz, Maria Cino, Nazira Chatur, Dana Farina, Andrea Faris, Samir Grover, Jamie Gregor, Adriana Lazarescu, Ralph Lee, Maitreyi Raman, Peter Rossos, Connie Switzer, Kevin Waschke, Geoff Williams, Clarence Wong, Brian Yan and trainee member Catharine Walsh. A subgroup of the committee designed the needs assessment survey, which was a modified version of the one used in 2010 .

The needs assessment was posted online and members were requested by e-mail to complete the simple 'tick box' survey. Data were compiled and analyzed at the CAG National Office.

The survey included three sections. The first collected basic demographic information; the second examined interest in topics for educational events; and the third section explored desired activities/formats for accredited learning activities.

Respondents were asked to rate their interest in 46 potential topics for educational events using a five-point scale of no interest, minor interest, neutral/not sure, some interest, and very interested. They were also queried regarding how CAG should interact with provincial/regional gastroenterology organizations, CAG's provision of Maintenance of Certification (MainCert) credits, the ePortal and preferences for CDDW venues.

\section{RESULTS}

A personalized e-mail request sent to CAG members in mid-March drew 205 respondents, representing 20\% of the solicited membership.

\section{Demographics}

Virtually all respondents were CAG members (96\%) and 63\% were male. Regarding education, $75 \%$ held an MD or equivalent degree, $21 \%$ and $15 \%$ held a $\mathrm{PhD}$ or $\mathrm{MSc}$, respectively, while $7 \%$ held another degree. Of the 156 respondents for whom the question was applicable, the year of medical school graduation was before 1970 for $6 \%, 1970$ to 1979 for $13 \%, 1980$ to 1989 for $22 \%, 1990$ to 1999 for $22 \%$, and 2000 or later for $36 \%$. Most respondents were predominantly based at teaching hospitals (62\%), rather than being community based with $(20 \%)$ or without (3\%) hospital privileges, while 15\% answered 'not applicable'.

Most replies were from individuals in Ontario (37\%), followed by Alberta (20\%), Quebec (19\%) and British Columbia (11\%), with responses roughly distributed in proportion to provincial population.

Respondents' specialty was identified as adult gastroenterology by $47 \%$, pediatric gastroenterology by $9 \%$, hepatology by $0.5 \%$ and surgery by $1.5 \%$. Basic and clinical scientists comprised $20 \%$ and $1 \%$, respectively, of respondents. Residents and fellows accounted for $15 \%$, and 'Other' roles for $6 \%$.

Regarding where respondents spend their time, 51\% identified clinical practice as their primary focus and $27 \%$ noted basic research (ie, more than $50 \%$ of their time performing research). Clinicianresearchers $(50 \%$ or less time performing research) formed the next largest group at $6 \%$, followed by clinician-teachers $(50 \%$ or less time teaching) at $5 \%$. Less commonly individuals were involved in clinical research (more than $50 \%$ of the time) (4\%), teaching (more than $50 \%$ of the time) (1.5\%), administration (more than $50 \%$ of the time) $(0.5 \%)$ or 'other' duties $(5 \%)$.

\section{Educational topics}

The percentage of respondents who were 'very interested' in each topic are shown in Figures 1 to 4 for the 46 educational topics surveyed. Consistent with previous years, IBD topics remain extremely popular and, apart from IBD, celiac disease, endoscopic techniques and live endoscopy were among the most desired educational areas (Figure 1). Most-desired topics according to various demographic splits (adult versus pediatric gastroenterologist and basic scientists) are presented in Table 1.

\section{Learning activities/formats}

Regarding how CAG should interact more with provincial/regional gastroenterology organizations, 68\% selected 'providing speakers/content

\section{The CAG is proud to acknowledge its Benefactor Corporate Sponsors:}

Abbott Canada
AstraZeneca Canada Inc
Olympus Canada Inc

Merck \& Co Inc
Takeda Canada Inc 


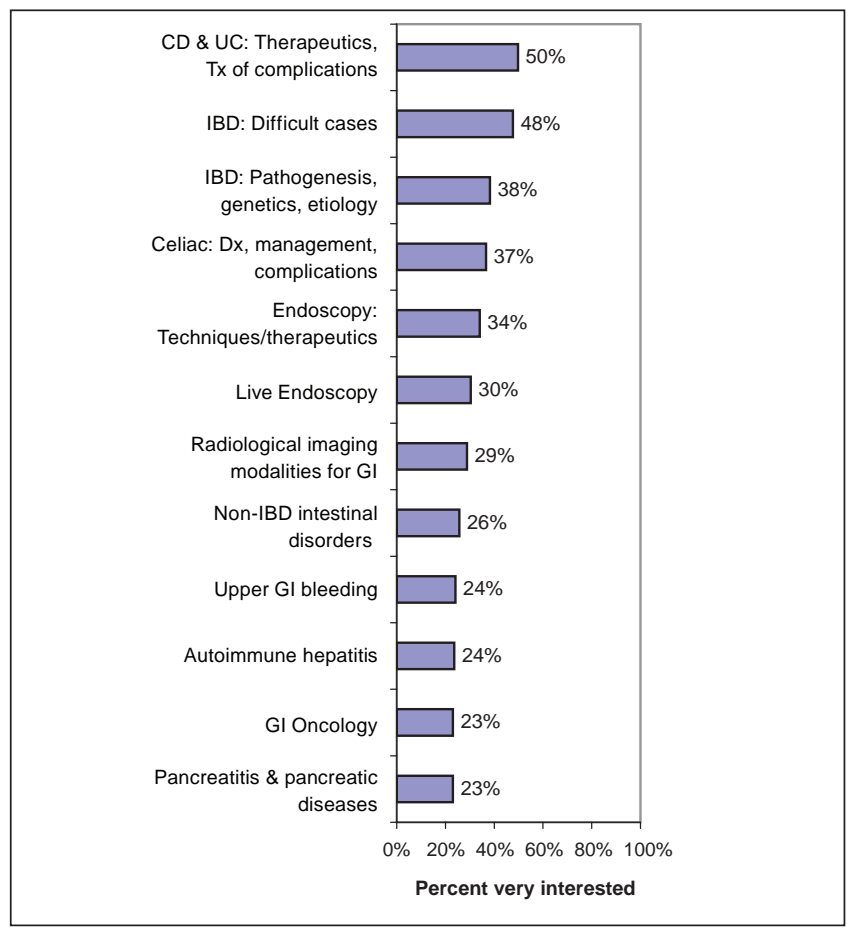

Figure 1) ) The 12 most popular topics for educational events based on the percentage of respondents who were 'very interested' in the area. CD Crohn's disease; Dx Diagnosis; GI Gastrointestinal; IBD Inflammatory bowel disease; Tx Treatment; UC Ulcerative colitis

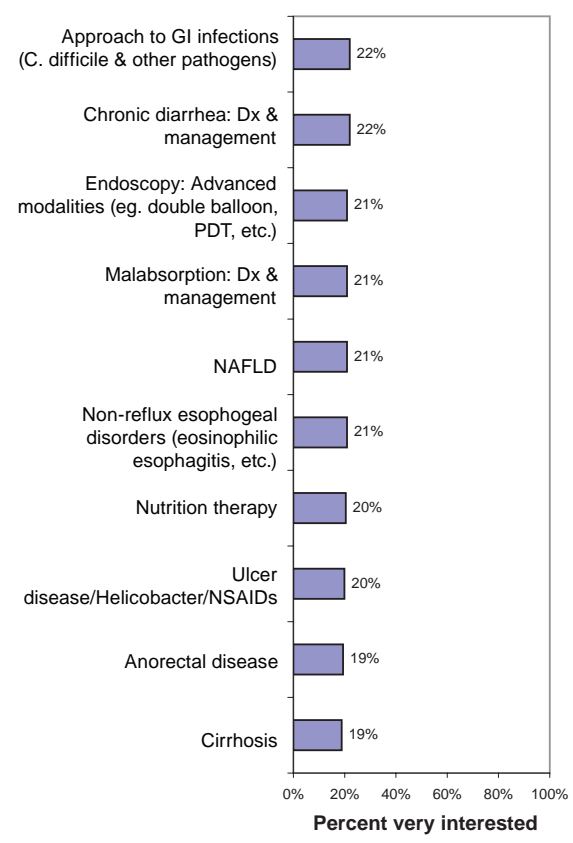

Figure 2) Educational topics in which $19 \%$ to $22 \%$ of respondents were 'very interested'. C. difficile Clostridium difficile; Dx Diagnosis; GI Gastrointestinal; NAFLD Nonalcoholic fatty liver disease; NSAIDs Nonsteroidal anti-inflammatory drugs; PDT Photodynamic therapy

for provincial/regional meetings', 53\% selected 'recording of provincial/ regional meetings for online educational activities', $26 \%$ noted combined collection of membership fees and 6\% listed an 'other' suggestion.

New this year, members were asked about their preference regarding the type of CDDW venue: 37\% selected 'Resort', 26\% wanted a 'Major airport hub' and $37 \%$ said it did not matter.

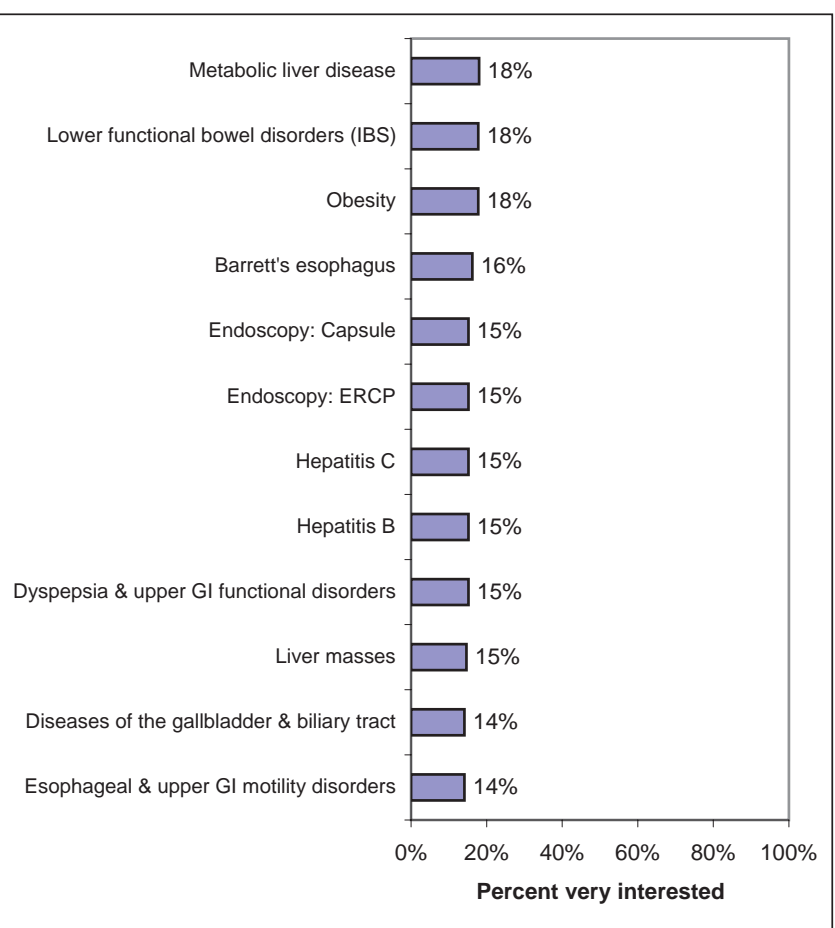

Figure 3) Educational topics in which $14 \%$ to $18 \%$ of respondents were 'very interested'. ERCP Endoscopic retrograde cholangiopancreatography; GI Gastrointestinal; IBS Irritable bowel syndrome

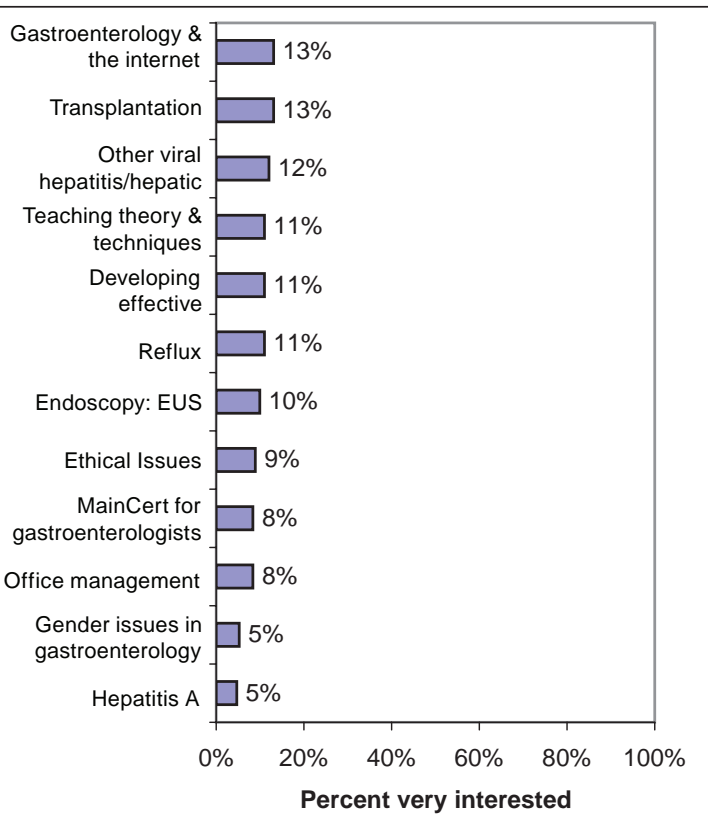

Figure 4) Educational topics in which 5\% to $13 \%$ of respondents were 'very interested'. EUS Endoscopic ultrasound; MainCert Maintenance of certification

The majority of respondents (70\%) for whom the question was applicable (61\% [116 of 191]) noted that they rely on CAG for less than one-half of their MainCert credits (Figure 5). Regarding the question "Would it be of benefit if CAG provided review and Section 3 RCPSC accreditation approval for external (AGA, ACG, ASGE, etc) self assessment programs?" $83 \%$ of applicable respondents answered 'Yes'.

Regarding the CAG's ePortal, 52\% were aware of its launch in September 2009 and $31 \%$ had visited the site. Of those who had 


\section{TABLE 1}

Most popular educational topics according to respondent subgroup

\begin{tabular}{|c|c|c|c|c|c|}
\hline \multirow[b]{2}{*}{ Group } & \multicolumn{5}{|c|}{ 'Very interested', \% } \\
\hline & First choice & Second choice & Third choice & Fourth choice & Fifth choice \\
\hline $\begin{array}{l}\text { Adult gastroenterologists } \\
(\mathrm{n}=91)\end{array}$ & $\begin{array}{l}\text { IBD difficult cases } \\
(57.1)\end{array}$ & $\begin{array}{c}\text { Crohn's disease/UC } \\
\text { therapeutics (50.5) }\end{array}$ & $\begin{array}{l}\text { Endoscopy techniques/ } \\
\text { therapeutics (48.4) }\end{array}$ & Live endoscopy (42.9) & Celiac disease (37.4) \\
\hline Basic scientists $(n=36)$ & $\begin{array}{l}\text { IBD pathogenesis, } \\
\text { genetics, etiology (52.8) }\end{array}$ & $\begin{array}{r}\text { Crohn's disease/UC } \\
\text { therapeutics (33.3) }\end{array}$ & $\begin{array}{c}\text { Ulcer disease/Helicobacter } \\
\text { pylorilNSAIDs (25.0) }\end{array}$ & $\begin{array}{l}\text { Approach to GI infections } \\
(22.2)\end{array}$ & $\begin{array}{l}\text { Obesity (19.4) } \\
\text { GI oncology (19.4) } \\
\text { IBD difficult cases (19.4) }\end{array}$ \\
\hline
\end{tabular}

IBD Inflammatory bowel disease; GI Gastrointestinal; NSAIDs Nonsteroidal anti-inflammatory drugs; UC Ulcerative colitis

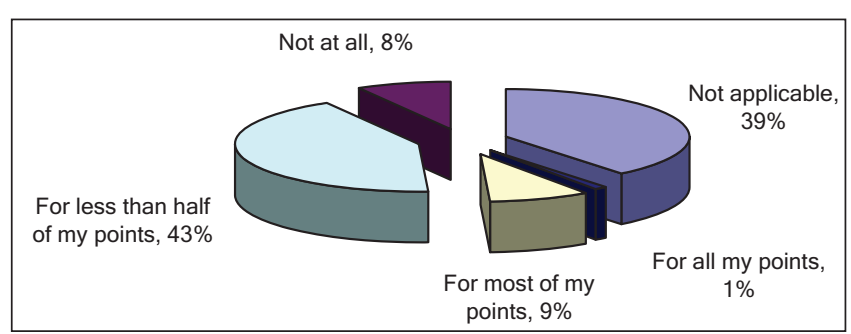

Figure 5) Responses to the question "How much do you rely on the CAG to provide you with Maintenance of Certification credits?"

visited the ePortal, 92\% agreed that they would visit the site again, $92 \%$ found the site easy to navigate and $90 \%$ found the educational content to be of value.

\section{DISCUSSION}

Twenty per cent of the solicited membership participated in the survey. An ongoing priority for Education Affairs is to develop innovative and easy assessment tools to encourage greater participation by members to accurately reflect their educational needs.

IBD remains the highest priority of respondents despite yearly CDDW sessions in this area since 2002. Apart from IBD, celiac disease, endoscopic techniques and therapeutics, and live endoscopy were popular. CAG Education Affairs is actively working to increase the quantity and quality of educational materials and programs that members can use as part of their ongoing maintenance of certification activities. These findings, along with evaluations of CDDW 2011 and identification of unrecognized educational needs, will form the basis of the 2012 CDDW program. 


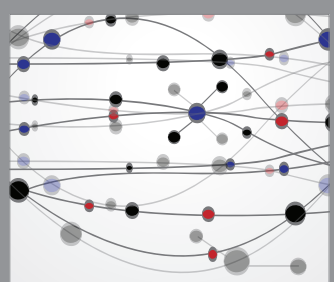

The Scientific World Journal
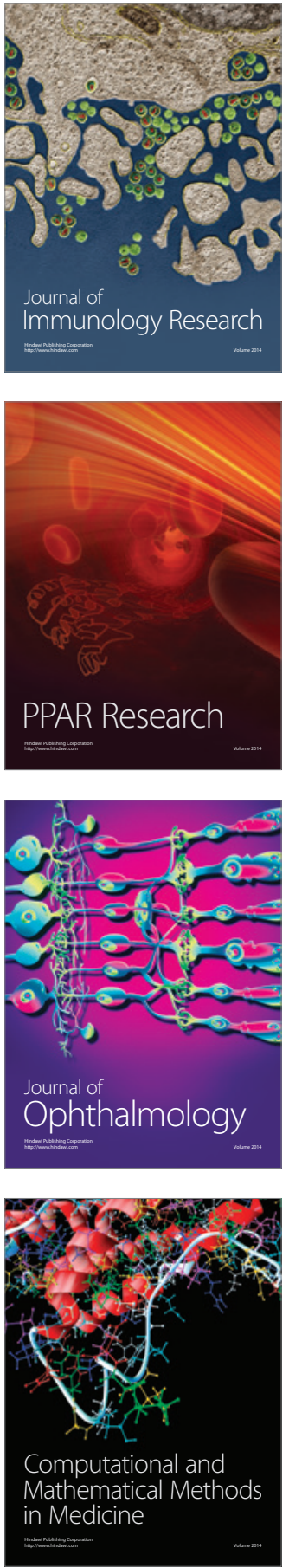

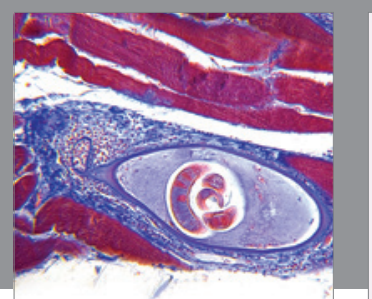

Gastroenterology Research and Practice

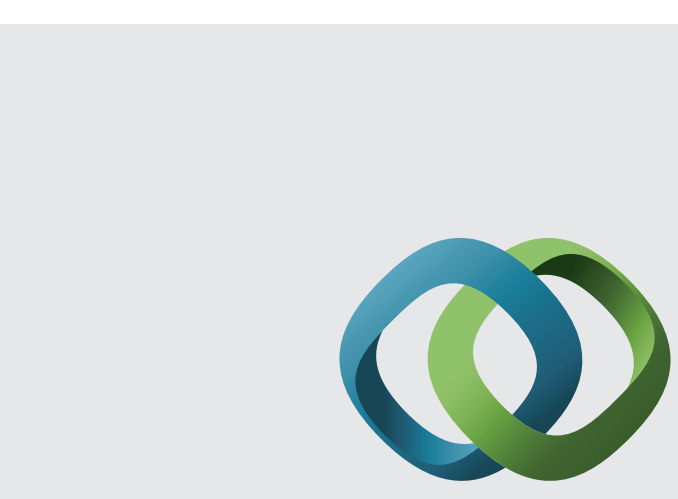

\section{Hindawi}

Submit your manuscripts at

http://www.hindawi.com
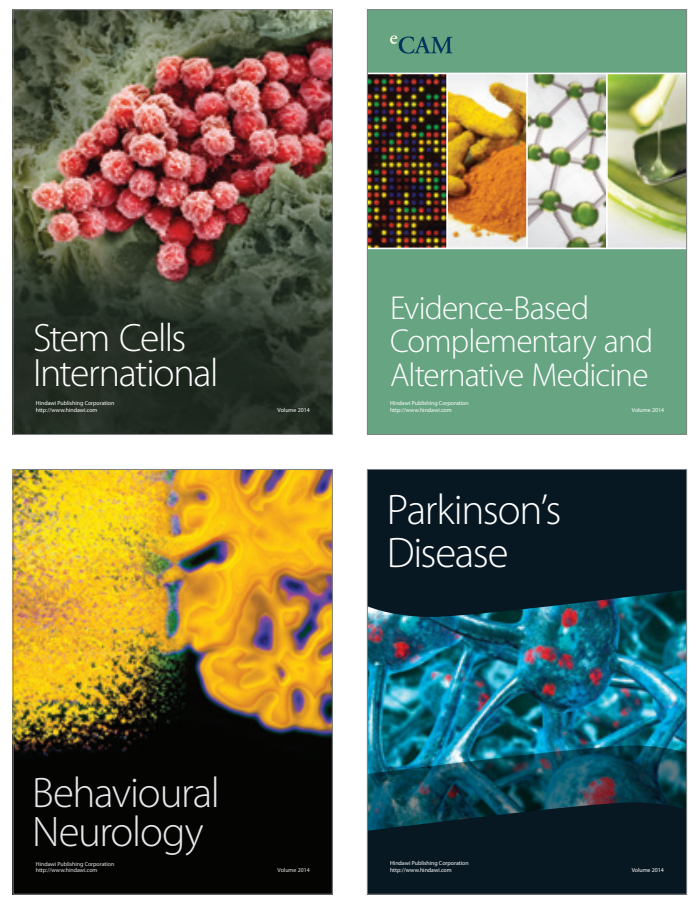
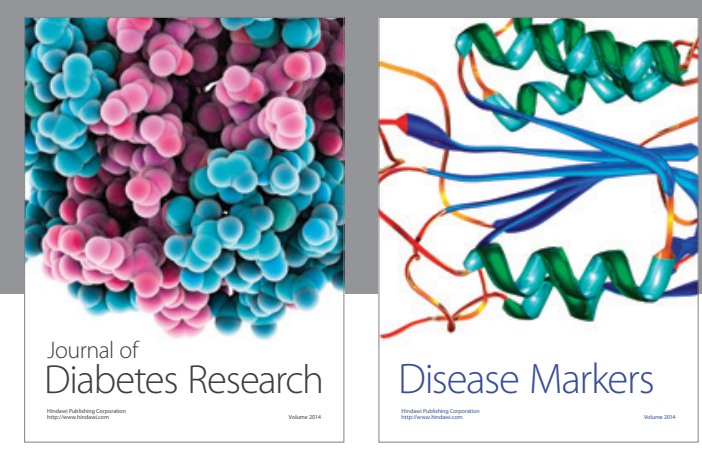

Disease Markers
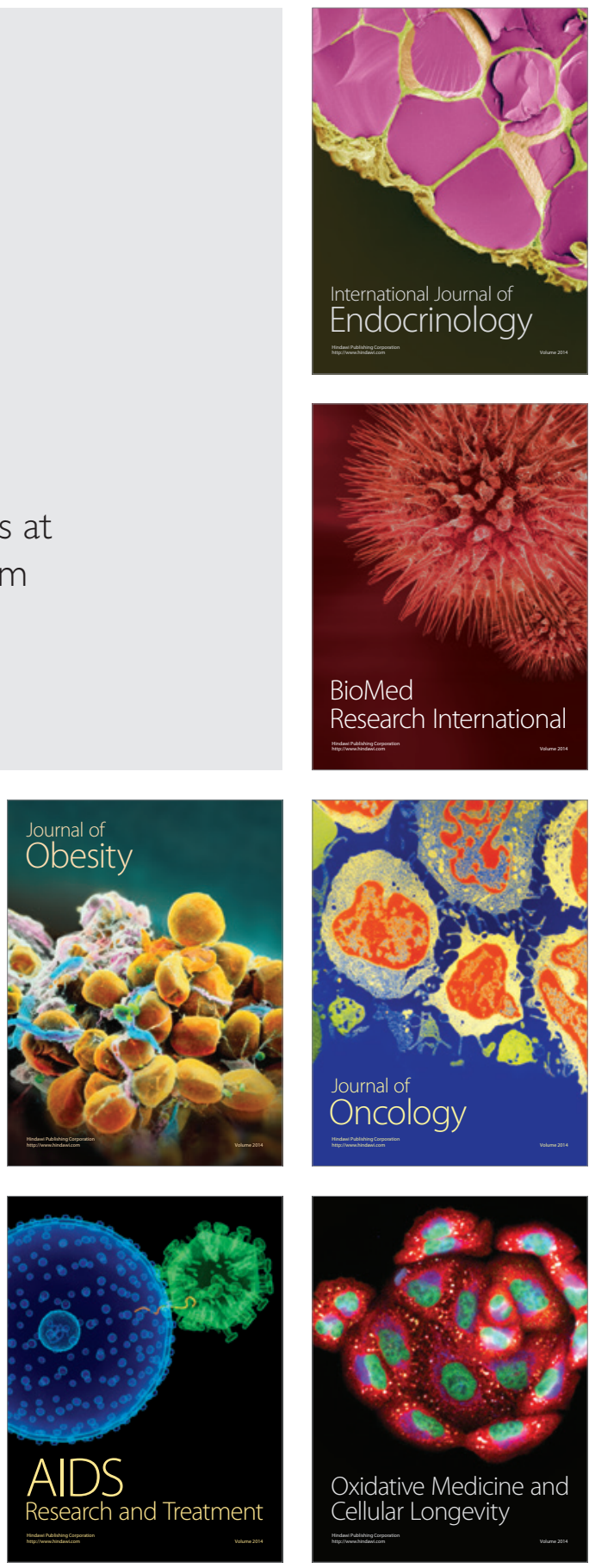